\title{
Determinants of Firms' Capacity Utilization in Ethiopia
}

\author{
Tadele Alamneh $^{1^{*}} \quad$ Degiye Goshu ${ }^{2} \quad$ Tora Abebe $^{3}$ \\ 1. PhD candidate in Economics; Debremarkos University, Ethiopia (corresponding Author) \\ 2. $\mathrm{PhD}$ in Agricultural Economics; Ethiopian Economics Association, Ethiopia \\ 3. PhD in Industrial Economics; Arba Minch University, Ethiopia \\ E-mail address: - alamnehtadele@gmail.com
}

\begin{abstract}
Under-utilization of firms in Ethiopia is an overriding problem which requires empirical evidence pertinent to capacity utilization policy formulation and implementation. Capacity utilization of firms in developed countries ranges from 85 to $100 \%$ while in developing countries it is about 65 to $84 \%$. In spite of these, firms' capacity utilization of less developed countries ranges from 50 to $64 \%$ while Ethiopian firm's capacity utilization is only $36 \%$ which is by far the lowest compared to the other world. This under-utilization of firms is the quest for knowing triggering factors. This paper investigates determinants of capacity utilization of firms where the data was collected by the World Bank from 848 firms in 2015 in all regions of the country. Capacity utilization (\%) and number of hours of operation per week were measured to capture the determinants of overall capacity maneuver. A seemingly unrelated regression (SUR) model result of multiple equation estimation of the two measures suggested that about $73.64 \%$ and $53.57 \%$ of the variation, respectively, in capacity utilization and number of hours operated per week were explained by SUR model. The determinant factors which are idiosyncratic to both measures were cost of input measured in monetary terms as a proxy variable for quantity of intermediate goods and raw material, the percentage share of domestic inputs for the establishment, annual fuel cost and access to credit were contributing positively and significantly. However, foreign exchange constraint and foreign input were attributed to affect significantly but have adverse effect for both of the outcome variables. Moreover, capacity utilization and number of hours of operation have positive interdependency. The major contribution of this paper is to employ econometric estimation of capacity utilization and number of hours of operation per week and measures their interaction as well as identifies its determinants at firm level.
\end{abstract}

Keywords: capacity utilization, number of hours of operation per week, seemingly unrelated Regression (SUR), multiple equation models

DOI: $10.7176 / \mathrm{JESD} / 13-3-02$

Publication date: February $28^{\text {th }} 2022$

\section{INTRODUCTION}

Capacity utilization is a concept in economics which refers to the extent to which an enterprise or a nation actually uses its installed productive capacity. Different scholars define capacity utilization in different ways though they have similar theme. Satik (2017), define as capacity utilization is the extent that an enterprise or a country puts its installed production capacity to use. It also refers to the relationship between the actual output produced and the maximum potential output

According to Okpaleye (1988), Capacity utilization in firms is described as "the level of utilization of a firm's installed productive capacity". Thus, it refers to the relationship between actual output produced and potential output that could be produced with installed equipment."

On the other viewpoint, capacity utilization is defined from the perspective of cost principles where at each level of production, firm will choose its level of utilization based on the principle of cost minimization and then explores how such will determine its normal rate of utilization (Nikiforos, 2012). Thus, an increase in capacity utilization means a reduction in the average cost of production (Afroz and Roy, 1976).

In theory, capacity utilization is measured in $100 \%$ efficiency level, however, in practical sense, capacity utilization may not exceed $90 \%$ maximum level especially in all types of economies due to some setbacks in the production process such as lack of proper labor monitoring and supervision, wastages in the process and machine breakdown (Afroz and Roy, 1976). However, empirical evidences show that average capacity utilization of developed countries ranges from 85 to $104.1 \%$ where Japan is operating over capacity utilization (104.1\%), middle income countries (BRICS) ranges from 64 to 85\% and less developed countries is about 32 to $65.6 \%$ (Trading economics, 2017). In particular case Ethiopia's firm's capacity utilization is only about 36\% (Solomon, 2018).

In general capacity utilization plays a crucial role in evaluating economic performance of different firms. It is an important factor to be considered when an increase in productivity and expansion of firm's production become necessary. Therefore, in the realm of capacity utilization concept, identifying the determinant factors is the leading concept to be considered how factors and to what extent they affect the entire capacity utilization of firms is paramount. Hence, identifying the determinants of capacity utilization is supreme to explain investment behavior, productivity movements, cost-push inflation and inventory behavior, and are often used as indicators of the 
strength of aggregate demand. Despite the fact that it is a vital economic indicator, capacity utilization has not received due attention from development economists especially in most developing countries, Ethiopia inclusive. Therefore, there is gap of knowledge about the determinants of capacity utilization of firms and their order of importance. Thus, factors affecting capacity utilization remains an important concept, though often neglected, in the production process. Therefore, the objective of this study is to analyze the major possible determinants for capacity utilization of Ethiopian firms comprising major problems attributable to under-utilization against its potential capacity.

\section{METHODOLOGY}

\subsection{Data Set and Analytical Technique}

To analyze determinants of capacity utilization, descriptive analysis was applied. The data was taken from the Ethiopian enterprise survey collected by World Bank 2015 from 848 firms in all regions of the country. In this analysis data on variables such as: quantity of domestic input, input cost, fuel cost, number of permanent workers, number of competitive firms, frequency of water shortage, credit access(dummy), foreign exchange constraint(dummy), foreign input (dummy), electric power outage(dummy), colateral size was analyzed. Standard deviation and mean values are used for continuous explanatory variables and frequency and percentage for dummy variables in analyzing explanatory variables that determines capacity utilization.

\subsection{Empirical model specification}

The major outcome variables considered in the analysis include capacity utilization of firms in percent and the number of hours of operation per week. Capacity utilization and number of hours of operation per week of Ethiopian firms were generally hypothesized to be determined by supply and demand factors. As such, the expected determinants of capacity utilization of firms and the number of hours of operation per week are electricity outage(dummy), quantity of raw materials and intermediate goods used in production, demand for products (domestic demand), annual total cost of fuel, access to credit (dummy), number of permanent workers, colateral size, number of competitive firms, foreign exchange constraint (EXCGdummy), frequency of water shortage, foreign input (Rukhsana, 1998; P.A. Adeyemi1 and O.B. Olufemi, 2016; Okunade, 2018; Guo-liang, Y. et al. 2019).

The primary reason of simultaneous estimation of determinants of capacity utilization and number of hours of operation per week was designed to identify the relationship between capacity utilization and number of hours of operation per week with its covariates. To account for this multiple equation regression, the two equations were estimated by seemingly unrelated regression (SUR) model (Zellner, 1962; Greene, 2012):

The model of prediction that signifies factors that determine capacity utilization and number of hours of operation per week of firms' attempts to estimate using seemingly unrelated regression (SUR) model collected from cross sectional data of 848 firms. The main question under consideration is what factors determine capacity utilization of Ethiopian firms that do not utilize its full capacity with the existing stock of capital. To test the various hypothesis concerning factors affecting capacity utilization, it is specified in the following form;

$C U=\alpha_{l}+\beta_{1}$ OUTPMdummy $+\beta_{2}$ domesticinput $+\beta_{3}$ competition $+\beta_{4}$ domesticsale

$+B_{5}$ creditdummy $+\beta_{6}$ colateral $+\beta_{7}$ FRGNINPT $+\beta_{8}$ lninputcost $+\beta_{9}$ lnfuelcost

$+\beta_{10}$ EXCGdummy $+e$

NHOPWEEK $=\alpha_{l}+\beta_{1}$ OUTPMdummy $+\beta_{2}$ domesticinput $+\beta_{3}$ lnwater $+\beta_{4}$ domesticsale

$+\beta_{5}$ creditdummy $+\beta_{6}$ permworker $+\beta_{7}$ FRGNINPT $+\beta_{8}$ lninputcost $+\beta_{9}$ lnfuelcost

$+\beta_{10}$ EXCGdummy $+e$

(4)

Where: $C U$ is capacity utilization of firms; NHOPWEEK is Number of hours of operation per week; OUTPMdummy is Electricity outage per month; domesticinput: Quantity of raw materials and intermediate domestic goods used in production in percent; competition is number of competitive firms; domesticsale is domestic demand for firms' product; creditdummy is access to credit; colateral is size of the colateral required by credit institutions; FRGNINPT is foreign input; lninputcost is percentage use of domestic input (log transformed); Infuelcost is total annual cost of fuel (log transformed); EXCGdummy is foreign exchange constraint (dummy); lnwater is water availability (dummy).

\section{RESULTS AND DISCUSSION}

\subsection{Descriptive Result Analysis}

The overall performance of firms' capacity utilization is on average at $26.54 \%$ despite the fact that there are significant differences among themselves ranging from $1 \%$ to $100 \%$ in its potential capacity and the standard deviation is 32.31 while in the case of number of hours of operation per week (NOHPWEEK), the average number of working hours of operation is about 36.58 hours. The maximum number of hours of operation per week is 168 hours and the minimum is 15 hours indicating wider range of performance with standard deviation of 33.38 . 
The percentage sale of domestic firms indicates that the total sale product of a particular product from its total output in a given time implies the demand for the product of the firm. The market demand for the product ranges from minimum sale of zero percent to 100 percent domestically with mean of about $93 \%$ and the standard deviation $22.8 \%$. The implication is that there is larger domestic demand of the products. The number of competitive firms for similar product ranges from zero competitor to a maximum of 200 competitive firms producing similar output. The mean competitive firms of the sample are around 2.88 with a standard deviation of 9.6. The sample firms undertaken in the study has permanent with full-time employed workers having the maximum number of 7600 employees and minimum number of 1 worker with mean of about 93 and standard deviation about 372 workers. The percentage share of using domestic inputs for firms output ranges from 1 percent to 100 percent and the average domestic input application by the firms is about $33.7 \%$ with standard deviation of $43.2 \%$. Input cost is the quantity of raw and intermediate goods used in the production process in monetary terms. The maximum amount of cost of input is 717,000,000 and the minimum is 5,000 with mean 14,000,000 and standard deviation $60,200,000$.

The amount of annual fuel cost billed for generator in order to maintain the production of the firms' output is the maximum cost of 364,000,000 birr and minimum cost of zero with average mean for samples is 2,277,522 birr with standard deviation of 20,700,000. The implication is that because of the existence of load-shedding effect and electric power outage, firms are using much fuel for the generator.

Colateral is the amount of asset required by financial institutions for the loan they deliver to firms. The price of assets required by lenders for the sample firms has minimum of zero and maximum value of 30,000,000,000 with average mean of 45,900,000 and standard deviation of 1,030,000,000 birr.

Table 1: descriptive table of continuous explanatory variable of the model

\begin{tabular}{lccclc}
\hline Variable & Obs & Mean & Std. Dev. & Min & Max \\
\hline domesticsale (\%) & 848 & 93.07547 & 22.80525 & 0 & 100 \\
Competition & 848 & 2.883255 & 9.62873 & 0 & 200 \\
Permworker & 848 & 92.64151 & 371.6163 & 1 & 7600 \\
Fuelcost & 848 & $2,277,522$ & $20,700,000$ & 0 & $364,000,000$ \\
Inputcost & 848 & $14,000,000$ & $60,200,000$ & 5,000 & $717,000,000$ \\
colateral| & 848 & $45,900,000$ & $1,030,000,000$ & 0 & $30,000,000,000$ \\
Domesticinput (\%) & 848 & 33.67807 & 43.24444 & 1 & 100 \\
\hline
\end{tabular}

Source: Author's computation, 2021

The variable power outage is included as dummy variable whether the firm experienced obstacles in relation to enhancement of its capacity utilization or not. From its chi square test, the variable is insignificant for both outcome variables of capacity utilization $(\mathrm{pr}=0.161)$ and for number of hours operated per week $(\mathrm{pr}=0.227)$. The implication is there is no capacity utilization differences between firms facing power outage obstacles and firms that don't face the obstacles.

Access to credit is the easiness for firms to get access to credit which is captured by the variable making it dummy that is expressed as those firms having access to credit with no obstacle accounts $42.69 \%$ of the total proportion while firms that have obstacles to get credit are $57.3 \%$ for their capacity utilization. The chi square test shows that access to credit is not significant at 5\% level indicating that credit access doesn't have significant difference between those who have obstacle and who don't have obstacles for their capacity utilization $(\mathrm{pr}=0.718)$ as well as the variable is also insignificant for the number of hours operated per week $(\mathrm{pr}=0.457)$.

Foreign exchange is a dummy variable that firms that are earning foreign exchange without any obstacle are $40 \%$ whereas firms that faced obstacles are $60 \%$ indicating that majority of firms are facing obstacles to get foreign exchange. The chi square test substantiated the fact that firms getting foreign exchange with no obstacle are significantly different at less than $5 \%$ level for capacity utilization $(\mathrm{pr}=0.03)$. The implication is that firms that are dominantly dependent on foreign inputs are likely to be affected in their production capacity.

The variable foreign input is the dummy that whether the firm is used foreign input as factor of production or not. The number of firms that uses foreign inputs as factor of production is $23.23 \%$ while those who don't use foreign inputs were $76.77 \%$. The chi square test of the variable is significant at $1 \%$ level $(\mathrm{pr}=0.000)$. The implication is that firms that use foreign inputs have significance difference with their counterparts.

\subsection{Econometric Analysis}

The SUR model result demonstrated that the determinants enhancing capacity utilization were quantity of raw and intermediate goods(lninputcost), credit access (creditdummy), percentage share of domestic input(domesticinput), and cost of fuel for generator usage (lnfuelcost) all of which were in line with the expected signs. Factors adversely affecting households' capacity utilization were foreign input (FRGNINPT) and foreign exchange constraint (EXCGdummy). The negative effect of foreign input application and foreign exchange constraint in the production process of firms reflects the problem of Ethiopian context in connection with the balance of payment constrictions 
to get sufficient foreign currency due to the fact that the country is known for its balance of payment deficit and in dearth of delivering surplus foreign currency for firms as per their request/demand. The result of predicted value also depicts that the index captured by capacity utilization is $26.54 \%$ to affect the overall determinant factors of firms' capacity utilization in Ethiopia.

\subsection{Linear interaction of capacity utilization and number of hours of operation per week}

Assuming that capacity utilization is correlated with number of working hours operated per week, underlying joint explanatory variables of firms' capacity utilization and number of hours of operation per week were identified by estimation of the multiple equation model of seemingly unrelated regression (SUR) of the two equations.

The cross-equation correlation of residuals was strongly significant at $1 \%$ level and the null that the two equations are independent was rejected, suggesting that their simultaneous estimation was appropriate. About $73.64 \%$ and $53.57 \%$ of the variation, respectively, in capacity utilization and number of hours operated per week were explained by SUR model.

According to seemingly unrelated regression (SUR) model output reported below, the common causal factors determining capacity utilization and number of hours of operation per week are percentage of domestic input (domesticinput), credit access (creditdummy), foreign input (FRGNINPT), quantity of raw and intermediate goods expressed in monetary terms (lninputcost), annual cost of fuel used when there is electricity outage (lnfuelcost) and foreign exchange obstacle (EXCGdummy). The result suggests that capacity utilization of firms and the numbers of hours operated per week are interdependent by $19.04 \%$ where their interdependency is positively correlated to affect overall capacity utilization of firms.

Domestic input (domesticinput): -This is the percentage of material inputs and supplies of domestic origin applied in the production process. The result depicts that percentage share of domestic input was significant at $1 \%$ level implying that an increase in the proportion of domestic input by $1 \%$ will increase both capacity utilization of firms and number of hours of operation per week of the establishment by $9.46 \%$, citrus paribus. The logic behind is that firms that use greater portion of domestic inputs don't face different challenges such as foreign exchange problem, customs problem, and others that hinders production. Hence, largest proportion of application of domestic input has positive relationship with capacity utilization and number of working hours of operation per week.

Credit access (creditdummy): - This variable is a dummy variable (firms having credit access $=1 ; 0$ otherwise). The likelihood of firms that have access to credit can increase the capacity utilization of firms by $7.5 \%$ and makes these firms to have greater number of working hours of operation by 7.5 hours per week compared to their counter parts. This is for obvious reason that, firms having credit access are better to be pertinent for purchasing of inputs such as labor, raw material and equipment. So, firms require financial source to increase their capacity utilization as well as increase number of working hours of operation per week. The finding is in conformity with Okunade, Solomon Oluwaseun, (2018).

Foreign input (FRGNINPT): - It is dummy variable. Firms that face obstacles to get foreign exchange $=1 ; 0=$ otherwise and the model output is significant at 5\%. The likelihood of firms those which could use foreign inputs as factor of production, their capacity utilization is decreased by $6.73 \%$ and the number of hours of operation per week would be decreased by 6.73 hours compared to their counterparts. The sign of the variable is as expected of the hypothesis and; the justification is that Ethiopia as a country is known for its foreign currency deficit to easily avail as per the demand of the needy since there is limited financial liberalization. Hence, firms which uses foreign inputs necessitates foreign currency but they face deterrents which creates obstruction in the production process that ultimately affects firms output and capacity utilization. The result is in conformity with (Kemal and Allauddin, 1974).

Input cost (Ininputcost): - According to this model it is proxy variable for the amount of intermediate goods and raw material used for the establishment in monetary terms. It is significant at $1 \%$ to affect capacity utilization of firms signifying that a $1 \%$ increase of input cost will result in the increase in capacity utilization by $0.011 \%$ and the number of working hours of operation per week of a firm would increase by 0.011 hours per week keeping other things constant and the sign of the coefficient is as of prior expectation. The premise of this is that, expected output is the resultant of an increased demand for these inputs which is manifested by an increase in the cost of the firm indicating that positive relationship is expected to prevail between capacity utilization and quantity of input. This result is in line with the findings of (Okunade, 2018).

Total annual cost of fuel (Infuelcost): - It is the total amount of expenditure incurred for purchasing of fuel for generator. The variable is entered as log transformed. The result (lnfuelcost) is significant at 5\% level and it infers that a $1 \%$ increase in consumption of fuel for generators increases the capacity utilization of firms by $0.006 \%$ and the number of hours of operation by 0.006 hours keeping other things constant. This is because of the co-existence of electricity power outage and load-shedding, firms do have two alternatives either interjecting of production and waiting for power or using generator to extend production without interruption. Therefore, firms prefer the latter option to have greater output though larger cost of fuel. Hence, greater output indicates greater capacity utilization 
of firms. The finding is in line with the findings of Adenikiju (1998) in Nigeria.

Foreign exchange constraint (EXCGdummy): - is dummy variable where firms that use foreign inputs have value of 1 and 0 ; otherwise. The likelihood of firms that face obstacles to get foreign exchange, the capacity utilization of firms is decreased by $3.39 \%$ and the number of hours of operation per week is decreased by 3.39 hours compared to their counter parts and it is significant at $5 \%$ level of significance. In contrast, firms that used larger proportion of inputs of domestic origin (domesticinput) is highly significant at $1 \%$ level and the implication is a $1 \%$ increase in the share of inputs of domestic origin makes the capacity utilization of firms to increase by $9.46 \%$ and number of hours of operation is increased by 9.46 hours per week, citrus paribus. The justification behind is that Ethiopia as a country is constrained by foreign currency to supply sufficient amount of foreign currency for those demanding it. This ultimately affects firms which are engaged in the production of goods and services which require hard currency. Therefore, firms that use foreign inputs are more likely to produce lesser output compared to their counter parts.

In terms of magnitude, the most important determinants were percentage share of domestic inputs (domesticinput) followed by credit access (creditdummy) and the quantity of raw and intermediate goods (lninputcost) and then cost of fuel for generator usage (lnfuelcost). In contrast, the highest explanatory variable that hinders capacity utilization and number of hours of operation per week of firms is application of foreign input (FRGNINPT) followed by foreign exchange constraint (EXCGdummy). Significant variables of capacity utilization and number of hours operated per week were generally in line with the empirical evidences by Adeyemi, P.A. \& Olufemi, O.B. (2016), Okunade and Solomon Oluwaseun (2018), Solomon, M. (2018) except their difference in magnitude.

Table 2: The seemingly unrelated regression (SUR) model estimation result

\begin{tabular}{lllll}
\hline Variable & \multicolumn{2}{c}{ Coefficient } & $\begin{array}{l}\text { marginal effect } \\
\text { (dy/dx) }\end{array}$ & $\begin{array}{l}\text { Standard } \\
\text { error }\end{array}$ \\
\cline { 2 - 5 } & CU & NHOPWEEK & 0.0872 & 1.5403 \\
\hline Poweroutage (OUTPMdummy) & 0.087269 & -0.5836682 & 0.4617 & $0.5773 * * *$ \\
Domestic input (domesticinput) & 9.461763 & 7.861426 & 9.4617 \\
Competition & 0.0071723 & & 0.0071 & 0.0601 \\
Domestic sale(domesticsale) & 0.0007689 & 0.0607738 & 0.0007 & 0.0255 \\
Credit access(creditdummy) & 4.094003 & 1.981806 & 4.0940 & $1.9744 * *$ \\
Colateral (LNCOL) & 0.12303 & & 0.1230 & 0.1269 \\
Foreign input dummy FRGNINPT & -6.732879 & -4.852776 & -6.7328 & $2.2247 * * *$ \\
Input cost (lninputcost) & 1.146574 & 0.5314326 & 1.1465 & $0.1696 * * *$ \\
Fuel cost (lnfuelcost) & 0.6073561 & 1.028083 & 0.6073 & $0.1962 * * *$ \\
Foreign exchange (EXCGdummy) & -3.392771 & -7.403271 & -3.3922 & $1.2967 * * *$ \\
Water availability (lnwater) & & 2.440345 & 0 & 0 \\
Permanent worker (permworker) & & 0.0131103 & 0 & 0 \\
constant & 1.67786 & 11.8611 & & \\
Fitted values (predict) & & & 26.54 & \\
Adjusted R & & & & \\
\hline
\end{tabular}

$* * *, * *, *$ are significant at $1 \%, 5 \%$ and $10 \%$.

Source: Author's computation, 2021

\section{CONCLUSION}

The major conclusion of this study is that there is significant under-utilization of firms' capacity in Ethiopian which is about $36 \%$. This is the major problem which is exacerbated in the overall economy of the country. The problem is not restricted at firm level only, but also depicted in the economic system of the country which contributed greater role for slower economic growth. There are different factors which are accountable for underutilization of firms' capacity to the maximum potential though there are not sufficient studies implying the major determinants of capacity utilization of firms in Ethiopia where the concerned stakeholders can take remedial measures. This study can be taken as a profound study to identify the determinants of capacity utilization.

The seemingly unrelated regression (SUR) model was employed to analyze idiosyncratic factors for capacity utilization and number of hours of operation per week. The SUR model result of simultaneous regression suggests that the two regressands are positively interdependent. The explanatory variables which attributed positive and significant contribution were cost of input, fuel cost, share of domestic input, credit access while factors hindering capacity utilization were foreign exchange constraint and foreign input usage. The interdependency between the two models was highly significant.

\section{RECCOMMENDATION}

It may be conditional that the current state of the economy in Ethiopia in terms of the country's political stability, 
government expenditure, external influences such as foreign exchange constraint and foreign input price shocks influence the trend of capacity utilization of firms. Therefore, government should focus on building the bounciness of the economy to global shocks and design mechanisms to provide incentives to support firms' activities to enhance capacity utilization in the economy. Optimum firms' capacity utilization should be the objective of every sector in Ethiopian economy and should be a policy focus by the government. Therefore,

1. Devising ways to facilitate optimal productive capacity of installed machinery and other resources in every sector would ensure full resource utilization and reduce wastage in the system. 2. Without loss of generality, the government should also be aware that the average capacity utilization of Ethiopian firms is only $36 \%$ beyond which one of the lowest performances in the less developed countries. Therefore, more incentives should be introduced especially for high capital-intensive industries to increase their output levels and reduce their cost of operations by providing tolerable foreign exchange, adequate infrastructures (such as electric power and water supply) and funding facilities.

\section{Declarations}

We declare that this article is our original work and all the resources of material used for the article have been dually acknowledged.

\section{Acknowledgements}

The author thanks Ethiopian Economic Association who provided the data.

Author's contributions

TA, DG and TA have designed the study, simulate the data, analyzed using STATA 14, and interpreted the document of the manuscript. Moreover, TA, DG and AT have contributed all literature work, reviewing, and editorial works. Therefore, TA, DG and AT are the only authors of this manuscript. All author(s) read and approved the final manuscript.

\section{Funding}

All costs of data collection for the study were covered by the researchers themselves.

\section{Availability of data and materials}

all data are included in the manuscript.

\section{Ethics approval and consent to participate}

not applicable.

Consent for publication

we agreed to publication in the journal of Economic Structure.

\section{Competing interests}

the authors declare that they have no competing interests.

\section{References}

Adeyemi, P.A. \& Olufemi, O.B. (2016). The determinants of capacity utilization in the Nigerian manufacturing sector. Journal of Economics and Sustainable Development, 7 (5), ISSN 2222-1700 (Paper) ISSN 2222-2855 (Online).

Adenikinju, A. F. (1996); Structural Adjustment Programme and Efficiency in the Nigerian Manufacture Sector: Lesson Beyond Adjustment, in Beyond Adjustment management of Nigeria Economy. Selected Paper of the 1996 Annual Conference of the Nigerian Economic Society.

Afroz, G. \& Roy, D. K. (1976). Capacity utilization in selected manufacturing industries of Bangladesh. The Bangladesh Development Studies, 4(2), 275-288.

Basu, S. \& Fernald, J. (2001). Why is productivity pro-cyclical? Why do we care?" In C.R.

Berndt, E.R. \& Morrison, C.J. (1981). Capacity utilization measures: underlying economic theory and an alternative approach. American Economic Review 71 (2): 48-52.

Bresnahan, T. \& Ramey, V. (1993). Segment shifts and capacity utilization in the U.S. automobile industry. American Economic Review 83, 213-218.

Cassels, J.M. (1937). Excess capacity and monopolistic competition. Quarterly Journal of Economics 51: 426443.

Coelli, T.J., Rao, D.S.P., O’Donnell, C.J. \& Battese, G. E. (2005). An introduction to efficiency and productivity analysis, 2nd Edition, New York, NY: Spring Science.

Coelli, T., Grifell-Tatje, E. \& Perelman, S. (2002). Capacity utilization and profitability: A decomposition of shortrun profit efficiency. International Journal of Production Economics, 79, 261-278.

Deb, A. K. (2014). Economic reforms, capacity utilization and productivity growth in Indian manufacturing sector. Global Business Review, 15(4) 719-746.

Fagnart, J., Licandro, O. and Portier, F. (1999). Firm heterogeneity, capacity utilization, and the business cycle. Review of Economic Dynamics, 2, 433-455.

Gu, W.L. \& Wang, W.M. (2013). Productivity growth and capacity utilization. Economic Analysis Research Paper 
Series, Catalogue No. 11F0027M No. 085, Statistics Canada, Ottawa.

Guo-liang, Y. et al. (2019). Estimating capacity utilization of Chinese manufacturing industries. https://www.elsevier.com/locate/seps

Hickman, Bert G. 1964, On a new mew method of capacity estimation, Journal of the American Statistical Association, 59, 529-549.

IMF (2012). Coping with high debt and sluggish growth, world economic outlook; October 2012; Washington DC, USA.

Johansen. L. (1968). Production Function and the Concept of Capacity. Collected Economie et Mathematique et Econometrie 2, 46-72.

Okunade, S.O. (2018). Effect of Capacity Utilization on Manufacturing Firms' Production in Nigeria.

P.A. Adeyemi1 and O.B. Olufemi (2016). The Determinants of Capacity Utilization in the Nigerian Manufacturing Sector.

Klein, L.R. (1960). Some theoretical issues in the measurement of capacity. Econometrica 28: 272-286.

Kumar, M. \& Basu, P. (2008). Perspectives of productivity growth in Indian food industry a data envelopment analysis. International Journal of Productivity and Performance Management, 57(7), 503-522.

Melfou, K., Theocharopoulos, A. \& Papanagiotou, E. (2009). Assessing productivity change with SFA in the sheep sector of Greece. Operation Research International Journal, 9(3)

Nasdaq Incorporation, (2012). What is the difference between a developed, emerging, and frontier market? Retrieved from http://m.nasdaq.com/article/what-is-thedifference- between-a- developed-emerging-andfrontier-market-cm140649

Nikiforos, M. (2012). The (Normal) rate of capacity utilization at the firm level. Levy Economics Institute Working Paper No. 737.

Rukhsana k. K. (1998). Factors affecting capacity utilization in manufacturing sector of pakistan: a survey analysis Satik, H. (2017). Capacity Utilization. Industrial Engineering Department, Dokuz Eylul University, Turkey.

Seguin, B. \& Sweet land, J. (2014). Drivers of Canadian food processing competitiveness macro factors and micro decisions. George Morris Centre, Retrieved from: http://www.georgemorris. org/publications/Project_2_Drivers_of_Canadian_Fo od_Processing.pdf.

Solomon, M. (2018). Analysis of causes for under-capacity production of the Ethiopian re-bar manufacturing industry. Addis Ababa University, Ethiopia. 